\section{Pulp Regeneration: The Ultimate Goal of Regenerative Endodontics}

Keywords: Pulp regeneration; Endodontics; Dental pulp; Root canal

Received: December 21, 2016; Accepted: December 26, 2016; Published: December 30, 2016

The dental pulp, this sophisticated tissue protected inside the tooth dentin, when is destroyed or dead causes a great deal of pain and suffering to the patient. The only viable treatment is either root canal treatment RCT or extraction. To eliminate infection and protect the decontaminated tooth from further deterioration, root canal treatment RCT is performed.

The conventional means of RCT means removing the pulp and packing the chamber with a plastic material. Regenerative endodontics uses the concept of tissue engineering to deliver biologically based regenerative endodontic treatment of necrotic immature permanent teeth resulting in continued root development, increased thickness in the dentinal walls and apical closure. The ultimate goal of regenerative endodontics is pulp regeneration.

Recombinant amelogenin protein can provide signals that regulate gene expression and modify the inflammatory response, as well as advance the repair mechanisms of odontoblasts. Mounir et al. [1] have developed a technology to use recombinant amelogenin protein to recruit the regenerative capacity of the patient, resulting in the regeneration of a complete pulp. The regenerated pulp is predicted to function identically to the one destroyed by disease thus transforming the tooth to a disease free state. This material closes the opened apex with a regenerated dentin bridge. The treated teeth show a regenerated complete dental pulp, and in turn, revitalize a dead tooth with all the nerves, blood vessels restoring tooth function eliminating any possibility of infection thus the tooth is less subject to material failure as is the case for RCT treated teeth.

\author{
Maha MF Mounir \\ Department of Oral Diagnostic Science, \\ King Abdulaziz University, Kingdom of Saudi \\ Arabia
}

\section{Corresponding author: Maha MF Mounir}

\section{Maha.f.mounir@gmail.com}

Professor of Oral Biology, Department of Oral Diagnostic Science, Faculty of Dentistry, King Abdulaziz University, Jeddah, Kingdom of Saudi Arabia.

Tel: 00966555707604

Citation: Mounir MMF. Pulp Regeneration: The Ultimate Goal of Regenerative Endodontics. J Orthod Endod. 2016, 3:1.

The regenerated pulp tissue that fills the pulp chamber and root canal eliminates sites that can harbor even minimally active biofilms that can form in root canal treated teeth. Biofilms can contain many different types of microorganism, such as bacteria that causes infection. A healthy apical tissue is regenerated forming the tooth attachment apparatus made of dentin, cementum, periodontal ligament (PDL) and bone. This tissue is the hole that allows the nerve tissue, with its accompanying blood vessels, to enter the tooth by regenerating a dent in bridge and stops any infection that is present restoring the root canals to a healthy state. This development in regeneration of a functional pulp-dentin complex will have a promising impact on efforts to retain the natural dentition. 


\section{Reference}

1 Mounir MMF, Matar MA, Lei Y, Snead ML (2016) Recombinant amelogenin protein induces apical closure and pulp regeneration in open-apex, non-vital permanent canine teeth. J Endod 42: 402-412. 